\title{
A study of thrombocytopenia in pregnancy
}

\author{
Komal Modi ${ }^{1}$, Jaydeep Chaudhari ${ }^{2 *}$, Disha Vaja ${ }^{2}$
}

\begin{abstract}
${ }^{1}$ Department of Obstetrics and Gynecology, GMERS Medical College, Himmatnagar, Sabarkantha, Gujarat, India ${ }^{2}$ Department of Obstetrics and Gynecology, Medical College, Sola, Ahmedabad, Gujarat, India
\end{abstract}

Received: 26 December 2019

Revised: 24 January 2020

Accepted: 29 January 2020

\author{
*Correspondence: \\ Dr. Jaydeep Chaudhari, \\ E-mail: jaydeepc83@gmail.com
}

Copyright: () the author(s), publisher and licensee Medip Academy. This is an open-access article distributed under the terms of the Creative Commons Attribution Non-Commercial License, which permits unrestricted non-commercial use, distribution, and reproduction in any medium, provided the original work is properly cited.

\begin{abstract}
Background: Thrombocytopenia is defined as low platelet count and if it is present during pregnancy can jeopardize the maternal and fetal outcome. Thrombocytopenia occurs in $6-15 \%$ of pregnancies. Causes of thrombocytopenia include gestational, idiopathic thrombocytopenia, preeclampsia, HELLP, DIC, malignancy and marrow failure. Aim of this study was to find out the common causes of thrombocytopenia in this hospital and management being used.

Methods: Data was collected form those women who came to the antenatal clinic (booked) and labour room (unbooked) in the department of obstetrics and gynecology, GMERS Medical College and Hospital, Sola, Ahmedabad. Data of a total of 75 pregnant women were collected during the period of July 2018 to June 2019.

Results: There were $66.67 \%$ cases of gestational thrombocytopenia, $13.33 \%$ related to preeclampsia, $8 \%$ in Eclamptic patients, $2.67 \%$ in HELLP and DIC, 6.67 in ITP, and lastly $2.67 \%$ in dengue cases. There were number of associated complication whether directly related (PPH) or part of the disorder. $\mathrm{PPH}$ was observed in $22.67 \%$ which is maximum among all complications. Other complications were part of major associated illness i.e. liver failure $(6.67 \%)$, renal failure (5.3\%), DIC (5.3\%) and HELLP (8\%).

Conclusions: Mode of delivery was not influenced by platelet count, but for obstetric indications. Management of patients was as per the diagnosis. Single donor plasma is preferable to random donor plasma. PPH was the commonest complication and we should be wary of that.
\end{abstract}

Keywords: Disseminated intravascular coagulation, Hemolysis elevated liver enzymes low platelet count, Preeclampsia, Postpartum hemorrhage, Thrombocytopenia

\section{INTRODUCTION}

Thrombocytopenia is defined as low platelet count. If present during pregnancy, it can jeopardize the maternal and foetal outcome. Thrombocytopenia affects $6-15 \%$ of pregnancies. The increasing report of thrombocytopenia is also be attributed to better antenatal check-ups and performance of investigation like complete blood count $(\mathrm{CBC}){ }^{1}$

It is defined as platelet count less than $150 \mathrm{X} 109 / 1$. Pregnancy does per se alter platelet level to a great extent, but few changes take place, which are more pronounced towards term. Causes of thrombocytopenia include gestational, idiopathic thrombocytopenia, preeclampsia, HELLP, DIC, malignancy and marrow failure. ${ }^{2-4}$

During pregnancy there is a general downward drift in platelet count, particularly during the last trimester. This result, at term, in a level that is approximately $10 \%$ less than the pre-pregnancy level. The mechanisms for this are thought to be a combination of dilutional effects and acceleration of platelet destruction across the placenta. Most women still have platelet counts within the normal 
range; however, if the starting count is at the lower end of the normal range, or there is a more severe drop, thrombocytopenia occurs. Hence thrombocytopenia is a common finding in pregnancy.

Most cases are mild and have no significance for mother or fetus but, in some instances, where thrombocytopenia is part of a complex clinical disorder, there can be profound and even life-threatening results for both mother and baby. The effect of pregnancy on the disorder and, conversely, of the disorder on the pregnancy, must be taken into account. In some instances, the aetiology is unique to pregnancy and the puerperium.

Aim of this study is to find out the common causes of thrombocytopenia in our hospital and management being used.

\section{METHODS}

Data was collected form those women who came to the antenatal clinic (booked) and labour room (unbooked) in the department of obstetrics and gynaecology, GMERS Medical College and Hospital, Sola, Ahmedabad. Data of a total of 75 pregnant women were collected during the period of July 2018 to June 2019.

Data collection was done on a pre-prepared proforma, which collected details of their antenatal history i.e., gestational age, risk factors, past obstetric history; and medical history i.e. viral infection, history of bleeding from gingiva, nose, skin petechiae, along with sociodemographic details. History of drug use was also taken. Thorough physical examination including obstetric examination was performed and noted. At the time of booking and labour room admission it is customary to do complete blood count of all gravid women in our set up. Routinely patients are investigated for HBsAg and HIV antenatally.

If thrombocytopenia was observed then patient was investigated further. Bleeding time, clotting time and coagulation test (PT, APTT) were done. Liver function test, renal function test and check-up for infections like dengue fever were done if symptoms were suggestive. Platelet count was repeated monthly if was found thrombocytopenic.

Patients were followed up through-out their gestational period. Feto-maternal outcomes were recorded. Any complication during antenatal period and delivery was noted. Mode of delivery, complications during delivery and postpartum complications in mother and NICU admission, neonatal outcome and birth weight of baby was recorded.

\section{RESULTS}

There were $66.67 \%$ cases of gestational thrombocytopenia, $13.33 \%$ related to preeclampsia, $8 \%$ in eclamptic patients, $2.67 \%$ in HELLP and DIC, $6.67 \%$ in ITP, and lastly $2.67 \%$ in dengue cases. This suggest that maximum number of patients were in gestational thrombocytopenia group followed by pre-eclampsia patients (Table 1).

Table 1: Classification of thrombocytopenia as per aetiology.

\begin{tabular}{|lll|}
\hline Cause & Number $(\mathbf{n}=\mathbf{7 5})$ & $\%$ \\
\hline Gestational & 51 & 66.67 \\
\hline Pre-eclampsia & 10 & 13.33 \\
\hline Eclampsia & 5 & 8 \\
\hline HELLP/DIC & 2 & 2.67 \\
\hline ITP & 5 & 6.67 \\
\hline Dengue & 2 & 2.67 \\
\hline
\end{tabular}

In this study majority of patients (56\%) were having platelets level between 1-1.5 lacs followed by $26.67 \%$ people having platelets level between 50000-1 lac. No case were noted with platelets level below 10000 (Table 2).

Table 2: Severity of thrombocytopenia.

\begin{tabular}{|lll|}
\hline Platelet levels & Number of cases & $\%$ \\
\hline$<10000$ & 0 & 0 \\
\hline $10000-50000$ & 13 & 17.33 \\
\hline $50000-100000$ & 20 & 26.67 \\
\hline $100000-150000$ & 42 & 56 \\
\hline
\end{tabular}

With $62.67 \%$ patients were in the age group between 18 26 follows by $33.33 \%$ between $26-35$ age group and lowest being $4 \%$ between $36-46$ years which suggests that chances of thrombocytopenia are more in the younger age groups (Table 3 ).

Table 3: Age.

\begin{tabular}{|lll|}
\hline Age in years & Number of cases & $\%$ \\
\hline $18-26$ & 47 & 62.67 \\
\hline $26-35$ & 25 & 33.33 \\
\hline $36-46$ & 3 & 4 \\
\hline
\end{tabular}

A total $65.33 \%$ were multipara and $34.67 \%$ were primi patients which suggests that chances of thrombocytopenia are higher in multigravida patients (Table 4).

Table 4: Parity.

\begin{tabular}{|lll|}
\hline Parity & Number of cases & $\%$ \\
\hline Primi & 26 & 34.67 \\
\hline Multi & 49 & 65.33 \\
\hline
\end{tabular}

There were number of associated complication whether directly related $(\mathrm{PPH})$ or part of the disorder. $\mathrm{PPH}$ was observed in $22.67 \%$ which is maximum among all complications. Other complications were part of major 
associated illness i.e., liver failure $(6.67 \%)$, renal failure (5.3\%), DIC (5.3\%) and HELLP (8\%) (Table 5).

Table 5: Maternal outcome.

\begin{tabular}{|lll|}
\hline Maternal complication & Number of cases & $\%$ \\
\hline PPH & 17 & 22.67 \\
\hline Liver failure & 5 & 6.67 \\
\hline Renal failure & 4 & 5.3 \\
\hline DIC & 4 & 5.3 \\
\hline HELLP & 6 & 8 \\
\hline Maternal death & 0 & 0 \\
\hline
\end{tabular}

Mode of delivery was decided based on the obstetric factors or medical factors. In this group there were $41 \%$ vaginal deliveries and rest were caesarean sections with $58 \%$ which suggests that caesarean sections were more (Table 6).

Table 6: Mode of delivery.

\begin{tabular}{|lll|}
\hline Mode of delivery & Number of cases & $\%$ \\
\hline Vaginal & 31 & 41.33 \\
\hline Caesarean section & 44 & 58.67 \\
\hline
\end{tabular}

Out of total 75 patients 45 number of patients delivered at term with $60 \%$ cases and 30 number of patients delivered prematurely with $40 \%$ cases. This suggest that babies delivered at term were greater in number than preterm (Table 7).

Table 7: Maturity of baby.

\begin{tabular}{|lll|}
\hline Maturity & Number of cases & $\%$ \\
\hline Term & 45 & 60 \\
\hline Preterm & 30 & 40 \\
\hline
\end{tabular}

\section{DISCUSSION}

Obstetric thrombocytopenia is a condition in which obstetric conditions i.e. severe preeclampsia. HELLP, DIC, abruption have resulted in thrombocytopenia whilst if it is ITP (Idiopathic thrombocytopenic purpura) then it is a medical condition to be dealt with during pregnancy.

Thrombocytopenia increases the risk of $\mathrm{PPH}$, while the other associated obstetric and medical conditions (mentioned above along with anaemia and sepsis) increase the risk of multiple organ failure and maternal mortality. ${ }^{5-7}$

Mode of delivery was not influenced by platelet count, but for obstetric indications. Caesarean sections were done for abruption, severe preeclampsia, eclampsia, previous caesarean section, failed induction or failed progress of labour.

Neonates were examined for any hematomas and investigated for platelet count. ${ }^{8}$
Random donor platelets or single donor platelets were used depending upon the availability.

In case of PPH blood and blood products were used.

Steroids were continued in patients of ITP with medical consultation.

Follow up was done by monthly platelet count.

Gestational thrombocytopenia is the commonest cause of low platelet during pregnancy but other medical disorder must be excluded by through history, physical examination, and investigations.

If thrombocytopenia was pre-existing then a medical disorder is more likely while if it develops during pregnancy gestational cause is more likely.

Primary immune thrombocytopenia was managed as per protocol. ${ }^{9}$

\section{CONCLUSION}

Mode of delivery was not influenced by platelet count, but for obstetric indications. Management of patients was as per the diagnosis. Single donor plasma is preferable to random donor plasma. PPH was the commonest complication and authors should be wary of that.

Funding: No funding sources

Conflict of interest: None declared

Ethical approval: The study was approved by the Institutional Ethics Committee

\section{REFERENCES}

1. Boehlen F. Thrombocytopenia during pregnancy. Importance, diagnosis and management. Hamostaseol. 2006;26(1):72-4.

2. Stirling Y, Woolf L, North WR, Seghatchian MJ, Meade TW. Haemostasis in normal pregnancy. Thromb Haemostas. 1984;52:176-82.

3. Matthews JH, Benjamin S, Gill DS, Smith NA. Pregnancy associated thrombocytopenia: definition, incidence and natural history. Acta Haematol Basel. 1990;84:24-9.

4. Fenton V, Saunders K, Cavillet I. The platelets count in pregnancy. J Clin Path. 1977;30:68-9.

5. Shehata N, Burrows RF, Kelton JG. Gestational thrombocytopenia. Clin Obstet Gynecol. 1999;42:327-34.

6. ACOG practice bulletin: diagnosis and management of preeclampsia in pregnancy. Obstet Gynecol. 2002;99:159-67.

7. Barton JR, Sibai BM. Diagnosis and management of hemolysis, elevated liver enzymes and low platelets syndrome. Clin Perinatol. 2004;31:807-33. 
8. Sullivan CA, Martin JN. Management of the obstetric patient with thrombocytopenia. Clin Obstet Gynecol. 1995;38(3):521-34.

9. Provan D, Stasi R, Newland AC, Blanchette VS, Maggs PB, Bussel JB, et al. International consensus report on the investigation and management of primary immune thrombocytopenia. Blood.

Cite this article as: Modi K, Chaudhari J, Vaja D. A study of thrombocytopenia in pregnancy. Int $\mathbf{J}$ Reprod Contracept Obstet Gynecol 2020;9:1115-8. 2010;115:168-86. 